\title{
Resistance screening trials on coconut varieties to Cape Saint Paul Wilt Disease in Ghana
}

\author{
Robert Nketsia QUAICOE ${ }^{1}$ \\ Sylvester Kuuna DERY ${ }^{1}$ \\ René PHILIPPE ${ }^{2}$ \\ LUC BAUDOUIN ${ }^{2}$ \\ Joseph Owusu NIPAH ${ }^{1}$ \\ Joe NKANSAH-POKU ${ }^{1}$ \\ Ransford ARTHUR ${ }^{3}$ \\ Daniel DARE ${ }^{1}$ \\ Egya Ndede YANKEY ${ }^{1}$ \\ Fabian PILET $^{2}$ \\ Michel DOLLET ${ }^{2}$ \\ ${ }^{1}$ CSIR- OPRI Coconut Programme, \\ P.O. Box 245, Sekondi, Ghana \\ $<$ rnquaicoe@yahoo.com> \\ ${ }^{2}$ CIRAD-Campus Int. de Bailarguet, TA80/A, \\ 34398 Montpellier cedex 5, France \\ ${ }^{3}$ CSDP, Min of Food \& Agric, \\ P.O. Box 245, Sekondi, Ghana
}

The coconut palm (Cocos nucifera $L$ ) is the "main stay" of the economies of the coastal belt of Chana [1, 2]. Due to the poor edaphic factors of this zone, coconut is usually the only crop that is commercially exploitable here [2]. The ability of the crop to create employment and spread wealth is common knowledge in the southern part of Ghana. It is, therefore, a major concern that the coconut industry in Ghana is threatened by the Cape Saint Paul Wilt Disease (CSPWD).

The CSPWD belongs to a group called lethal yellowing (LY), which also occurs in Togo, Nigeria, Cameroun, Tanzania and the Caribbean [3]. LY is known to be caused by phytoplasmas (non-culturable obligate parasites) and believed to be transmitted by insect vectors, notably plant and leaf hoppers (Homopterans $[4,5]$ ).

CSPWD was first reported in the country in 1932 at Cape Saint Paul in Woe in the Keta area of the Volta Region [6]. By 1934, 21 palms had been affected, the number rising to 476 by 1938 and in less than 10 years after its detection, it attained epidemic status, destroying about $9 \%$ of the coconut palms in that region [6]. The dis-

\begin{abstract}
The Cape Saint Paul Wilt Disease (CSPWD) is a coconut lethal yellowing type disease (LY) and is the single most serious threat to coconut cultivation in Chana. The recommended disease management strategy is the cultivation of disease-resistant coconut varieties. More than 38 varieties have been screened for their resistance to CSPWD since 1956 and the results are reviewed in this paper. Two varieties, Sri Lanka Green Dwarf (SCD) and Vanuatu Tall (VTT), have shown high resistance to the disease, and their hybrid (SCD $\times$ VTT) is under observation to determine its performance. A programme to rehabilitate the CSPWD-devastated areas was started in 1999. Emerging results indicate that the MYD $\times$ VTT hybrid being used for the programme, succumbs to the disease under intense disease pressure. A redirection of the rehabilitation programme and the screening of more varieties are recommended.
\end{abstract}

Key words: Chana, Cape Saint Paul Wilt Disease, coconut, resistance screening, varieties

ease next appeared in Cape Three Points in the Western Region, about $450 \mathrm{~km}$ from the initial focus, in $1964[6,7]$. The disease was confined to this area for about 5 years, before starting a rapid spread in an east-north direction, and a rather slower westward spread [6], and appeared at Ayensudo in the Central Region in $1983[8]$

The rapid spread of the disease from the initial focus in the Keta area and its devastating effect made CSPWD the single most serious threat to the coconut industry, prompting the Department of Agriculture of the Gold Coast to initiate scientific investigations into the disease in 1942. However, unable to determine the cause and mode of spread of the disease, it was concluded that search for resistant coconut varieties was the best option to follow [6]. Consequently, resistance screening was commenced in 1956. This research effort has been continued by various scientists, authorities and funding agencies up to the present time. The outcome of these trials up to 1995 led to the recommendation of the Sri Lanka Green Dwarf (SGD), Vanuatu Tall (VTT), SGD $\times$ VTT and MYD $\times$ VTT as suitable materials for rehabilitat- ing the devastated areas [9] At the time, only the MYD $\times$ VTT was readily available to be multiplied and released for the rehabilitation programme, even though its resistance level was not the best.

Emerging results now show that the MYD $\times$ VTT succumbs under intense disease pressure, thus calling for a redirection of the rehabilitation programme. Past results of the resistance screening trials have been published by various authors at different times. This paper seeks to review the earlier results of the resistance screening trials in Ghana, update the results of the current trials and discuss the prospects for future resistance trials and rehabilitation programmes.

\section{The highlights of past resistance screening trials}

\section{Trials of 1956-57 and 1966-69}

The Department of Agriculture established resistance screening trials at Ohawu, Dzelukope, Tegbi and Cape Saint Paul in the Keta area of the Volta Region in 1956-57. The varieties tested were Malayan Yellow Dwarf (MYD) and 
Malayan Green Dwarf (MGD), obtained from Malay (now Malaysia), and progenies of some West Africa Tall (WAT) that had survived in CSPWD-devastated areas [6, 7]. Except for the Dzelukope trial, all the other trials were abandoned due to heavy losses of the test palms. Initially, the MGD appeared to be less susceptible, but after the disease had run its full course, it became obvious that the MGD, MYD and the WAT were all susceptible to CSPWD (table 1).

Since the Malayan dwarfs were resistant to LY in Jamaica, it was opined that either LY and CSPWD were different diseases or that the MGD and MYD tested were not "true to type". Consequently in 1966, further screening ductions in 1964 and 1966 with "certified materials" (table 2). Flood destruction of most of the test palms necessitated the repeat of the experiment in 1969. Similar to the previous trial, all the varieties eventually succumbed to the disease, proving that dwarf varieties that had proven resistant to $L Y$ in Jamaica were susceptible to CSPWD at Dzelukope. Addison [7] and Harries [10] were of the view that the environmental conditions at the Dzelukope area could have made the test palms exceptionally susceptible to the disease. Harries [10] recommended that the Western Region should be the area to consider for resistance trials and that the Malayan dwarfs be reconsidered for testing.

\section{The 1977 trials}

Following from the Dzelukope experience, the Crop Research Institute planted a trial in 1977 at Cape Three Points in the Western Region, which was continued at Dzelukope with two intro-

had been an active disease focus since 1964 [7]. The varieties tested were Malayan Red Dwarf (MRD), MYD, and MGD from certified LYresistant mother palms in Jamaica, and WAT (as susceptible control). Some few Veitchia and Phoenix species were included in the trial. Also some wild oil palm undergrowths were inadvertently left to grow with the test palms. All the coconut palms were killed by the disease, but the other palm species survived [7].

\section{The 1981-83 trials}

Between 1981 and 1983, the Ministry of Agriculture, funded by the French Government under the France-Ghana-Ivory Coast Project, established seven resistance trials in the Western Region, using 27 varieties [11]. Situational reports of these trials have been published by Dery et al. $[9,13,14]$ and Mariau et al. [12] and updated in this paper. It took variable period of field exposure to effect disease in the affected plots. The Axim trial was affected after more than 20 years of planting, whereas Prince's (Princess) Town trial registered one death after 15 years of exposure, after which the disease has been dormant for the past 10 years. After 27 years of exposure to infection, the Dadwen trial is still "disease-free". With the exception of the Cape Three Points and Prince's Town trials, disease in all the affected trials entered into a dormant phase after a certain period of attack. At Akwidae, the dormant phase occurred 14 years after attack when disease level was $66 \%$. At Agona Junction, it was 6 years of attack with disease level at $65 \%$ and at Axim it was 4 years of attack

Table 1. Disease incidence in resistance trials at Dzelukope (1956-57 planting).

\begin{tabular}{|c|c|c|c|c|c|c|}
\hline \multirow[t]{2}{*}{ Variety } & \multirow{2}{*}{$\begin{array}{l}\text { No. } \\
\text { of test palms }\end{array}$} & \multicolumn{5}{|c|}{ Disease level (\%) } \\
\hline & & Mar 65 & Jun 65 & Feb 66 & Dec 66 & Feb 77 \\
\hline MGD & 10 & 8.3 & 8.3 & 50 & 92 & 100 \\
\hline MYD & 24 & 33.3 & 45.8 & 70.8 & 96 & 100 \\
\hline WAT & 33 & 42.4 & 48.5 & 87.8 & 91 & a \\
\hline
\end{tabular}

${ }^{a}$ Not available. Source: Computed from Chona and Addoh [6] and Addison [7].

Table 2. Disease incidence in resistance trials at Dzelukope (1967-69 planting).

\begin{tabular}{|c|c|c|c|c|}
\hline Variety & Source & No. of planted & No. of established & Resistance rating \\
\hline \multicolumn{5}{|c|}{1964 Introductions } \\
\hline MYD & Ivory Coast & 100 & 8 & Highly susceptible \\
\hline MGD & Ivory Coast & 100 & 14 & Highly susceptible \\
\hline CRD & Ivory Coast & 100 & 9 & Highly susceptible \\
\hline \multicolumn{5}{|c|}{1966 Introductions } \\
\hline WAT & Keta & a & 3 & Highly susceptible \\
\hline MYD & Jamaica & 60 & 14 & Highly susceptible \\
\hline MGD & Jamaica & 60 & 14 & Highly susceptible \\
\hline MRD & Jamaica & 60 & 15 & Highly susceptible \\
\hline
\end{tabular}

${ }^{a}$ Not available. Source: Computed from Chona \& Addoh [6], Addison [7] and Harries, [10]. with disease level at $83 \%$. The single death registered at Prince's Town was not confirmed by lab test and could possibly be a wrong diagnosis. The Cape Three Points location has always been an active disease focus with no dormant period reported. The performance of the varieties screened in the 1981-83 trials is summarized in table 3 . The resistance of the ecotypes and hybrids were rated according to the scheme of Been [15].

\section{The 1995 trials}

The CSIR-Oil Palm Research Institute, with funding from EC-STD III, planted two trials in 1995, one at Tumentu with 11 varieties and the other at Cape Three Points (at the old trial plot) with eight varieties. The Tumentu plot is still "disease-free" but the Cape Three Points plot was attacked in 2004 (9 years after planting). Situational report on this trial up to April 2006 has been published [14]. Table 4 is an update of the disease record in this trial. By April 2008, all the varieties under testing had been attacked by CSPWD to varying degrees. The most susceptible varieties were WAT: Ex-Benin and Indian Laccadive Tall (LCT), with Catigan Green Dwarf (CATD) and Tacunan Green Dwarf (TACD) showing relatively high level of resistance. Interestingly, three SGD palms, five each of Veitchia sp, Phoenix sp and Oil palm, which are remnants from the 1977 trial, were still free of CSPWD as at March 2008.

\section{The 2007 trials}

Under the FSP Project, funded by the French Government, eight varieties were introduced from Cote d'Ivoire in 2006. The new introductions comprised the following: MGD, Polynesian Red Dwarf, Indonesian Brown Dwarf, Niu Leka Dwarf, New Guinea Brown Dwarf, Thailand Green Dwarf, Cambodia Green Dwarf and New Guinea Green Dwarf. These together with SGD $\times$ VTT and the local WAT varieties have been planted for resistance screening at Asebu (Central Region), Nkroful (Western Region) and at the old trial plot at Cape Three Points (Western Region) in 2007. All three trial locations are active disease foci, and a computer generated completely randomized design was used to ensure uniform exposure of all varieties to infection; however, there is no CSPWD incidence as yet.

\section{The Rehabilitation Plantings}

\section{$S G D \times V T T$}

The high CSPWD resistance shown by the SGD and VTT varieties in the Dixcove trials (198183) led to the development of the SGD $\times$ VTT hybrid, which has been under screening at the Agona Junction plot since 1995. The hybrid 
Table 3. Disease incidence in the 1981/83 resistance trials.

\begin{tabular}{|c|c|c|c|c|c|c|c|c|}
\hline \multirow[t]{2}{*}{ Variety } & \multicolumn{5}{|c|}{ Disease level (\%) } & \multirow[b]{2}{*}{ TL. } & \multirow[b]{2}{*}{$\begin{array}{l}\text { Cm.Ds } \\
(\%)\end{array}$} & \multirow{2}{*}{$\frac{\text { Resist }}{\text { Rate }}$} \\
\hline & Ag.Jn. & Akwi. & Axim & Dixc. & C3Pts & & & \\
\hline 1.WAT & 98 & 82 & 100 & 100 & 100 & 155 & 96 & $\mathrm{HS}$ \\
\hline 2.MYD & 71 & 31 & - & 0 & 100 & 51 & 51 & LS \\
\hline 3.MRD & 11 & 0 & 0 & 57 & 100 & 45 & 34 & LR \\
\hline 4.CRD & 50 & 23 & - & 50 & 80 & 46 & 51 & LS \\
\hline 5.EGD & 72 & 0 & 33 & 29 & 100 & 42 & 47 & LR \\
\hline 6.SGD & 0 & 0 & 1 & 0 & 0 & 59 & 0.2 & $\mathrm{HR}$ \\
\hline 7.MYD × WAT & 96 & 100 & 100 & 100 & 100 & 83 & 99 & $\mathrm{HS}$ \\
\hline 8.MRD $\times$ WAT & 86 & 63 & 100 & 60 & 100 & 72 & 82 & LS \\
\hline 9.CRD × WAT & 67 & 96 & 100 & 86 & 100 & 75 & 90 & HS \\
\hline 10.EGD $\times$ WAT & 64 & - & 100 & 83 & 100 & 34 & 87 & $\mathrm{HS}$ \\
\hline 11.RNT $\times$ WAT & 83 & 95 & 90 & 100 & 100 & 89 & 94 & $\mathrm{HS}$ \\
\hline 12.SGD $\times$ WAT & 86 & 100 & - & - & 100 & 63 & 95 & $\mathrm{HS}$ \\
\hline 13.MYD $\times$ RNT & 0 & - & 100 & 100 & - & 13 & 67 & LS \\
\hline 14.CRD $\times$ RNT & 0 & - & 100 & 100 & - & 19 & 67 & LS \\
\hline 15.MYD $\times$ PYT & 33 & - & 100 & 100 & - & 13 & 78 & LS \\
\hline 16.CRD $\times$ PYT & 50 & - & 25 & 89 & - & 21 & 55 & LS \\
\hline 17.MRD $\times$ PYT & 41 & 40 & 71 & 33 & 100 & 67 & 57 & LS \\
\hline 18.CRD × VTT & 86 & - & 100 & 89 & - & 19 & 92 & HS \\
\hline 19.EGD × VTT & 67 & - & 83 & 89 & - & 24 & 80 & LS \\
\hline 20.MYD $\times$ VTT & 44 & - & 100 & 25 & - & 22 & 56 & LS \\
\hline 21.VTT $\times$ MLT & 83 & - & 83 & 63 & - & 20 & 76 & LS \\
\hline 22.CRD $\times$ MLT & 64 & 44 & 57 & 71 & 100 & 58 & 67 & LS \\
\hline 23.MYD $\times$ MLT & 60 & - & 100 & 18 & - & 23 & 59 & LS \\
\hline 24.MLT & 43 & - & 75 & 100 & - & 17 & 73 & LS \\
\hline 25.RNT & 56 & - & 88 & 100 & - & 20 & 81 & LS \\
\hline 26.PYT & 67 & - & 0 & 86 & - & 11 & 51 & LS \\
\hline 27.VTT & 0 & - & 100 & 13 & - & 21 & 38 & LR \\
\hline
\end{tabular}

TL: total number of palms tested from all the trials; Cu. Ds (\%): cumulated disease level (\%); Resist. Rate: disease resistance rating (after scheme of Been [15]); HR: highly resistant, disease level of less than 15\%; LR: less resistant, disease level $15-50 \%$; LS: less susceptible, disease level $16-85 \%$; HS: highly susceptible, disease level above $85 \%$.

Table 4. Cumulated disease incidence in the 1995 planting (as at April 2008).

\begin{tabular}{|lccll|}
\hline Variety & $\begin{array}{l}\text { No. of } \\
\text { observed }\end{array}$ & $\begin{array}{l}\text { No. of } \\
\text { affected }\end{array}$ & $\begin{array}{l}\text { Disease } \\
\mathbf{( \% )}\end{array}$ & $\begin{array}{l}\text { Resistance } \\
\text { rating }\end{array}$ \\
\hline 1. Indian Laccadive Tall (LCT) & 49 & 43 & 87.8 & $\mathrm{HS}$ \\
2. Indian Andaman Tall (ADOT) & 43 & 31 & 72.1 & $\mathrm{LS}$ \\
3. Panama Tall Monagre (PNT-02) & 35 & 12 & 34.3 & LR \\
4. Tagnanan Tall (TAGT) & 32 & 7 & 21.9 & LR \\
5. WAT Benin Type(WAT:EX-BENIN) & 56 & 52 & 92.9 & HS \\
6. Catigan green Dwarf (CATD) & 9 & 2 & 22.2 & LR \\
7. Tacuna Green Dwarf (TACD) & 10 & 1 & 10.0 & HR \\
8. Panama Tall (PNT-01) & 45 & 22 & 48.9 & LR \\
Total & 279 & 170 & 60.9 & \\
\hline
\end{tabular}

Resistance rating after scheme of Been [15].

was continuously exposed to CSPWD attack for 7 years, but after that, the disease became dormant in the plot. No incidence of CSPWD has occurred in this hybrid as yet; however, a "genetic modelling prediction" has designated it as a "promising hybrid" because of its expected low susceptibility to CSPWD [14].

\section{$M Y D \times V T T$}

As mentioned in the Introduction, MYD $\times$ VTT was used in a rehabilitation programme to prevent the total collapse of the coconut industry. The programme involved two activities, an initial adaptive trial, conducted by CSIR-OPRI, Coconut Programme, to "field-test" the resistance perfor- mance of the hybrid and a later more extensive replanting under the Coconut Sector Development Project (CSDP) of the Ministry of Food and Agriculture, with funding from Agence Francaise de Developpement (AFD). For the adaptive trials, 33 farmers within active CSPWD zones were assisted to plant 120 seedlings each, which were routinely monitored by scientists for a period of 8 years. Of the 33 farmers, 14 abandoned their farms, and final assessment of the performance of the hybrid was based on the records of 19 participants' farms. In these plots, mortality due to CSPWD was estimated as $1 \%$ [16], lending support to the decision to use the hybrid to revitalize the devastated coconut industry. Table 5 summarizes the results of the CSDP-MYD $\times$ VTT replantings. CSPWD has been confirmed in 62 ha, representing $4.8 \%$ of the total land cropped with the hybrid. Also 5.6\% of the total number of farms of the replanting programme had been attacked by the disease. However, only $0.002 \%$ of the actual number of "trees" originally planted had been affected. An exceptional case where CSPWD had killed 82\% of the palms was encountered at KEEA district.

\section{Discussion}

\section{Malayan Dwarfs}

The three 'colour forms' of Malayan Dwarfs, reported to be resistant to LY, were successfully used for a replanting programme in Jamaica [10]. Progenies of these varieties from LY-resistant mother palms that were screened in Ghana all succumbed to CSPWD at Dzelukope (1966-69) and Cape Three Points (1977). However, in the 1981-83 plantings, MRD showed varied resistance levels at the different trial locations (table 3). A genetic modelling analysis of the results of the 1981-83 trials, determined MRD as one of the most resistant varieties so far [14]. The obvious question that arises is whether the highly susceptible and highly resistant MRD encountered in these trials are genetically identical?

\section{WAT: Ex-Benin}

Benin, a LY-free country, is sandwiched between Awka disease of Nigeria and Kaincope disease of Togo. It was therefore speculated that the coconut germplasm of Benin exhibited resistance against the disease. At Cape Three Points, the WAT: Ex-Benin proved to be highly susceptible to CSPWD (table 4), thus disproving the earlier assumption.

\section{Prospects for rehabilitating the coconut industry}

Through a genetic modelling analysis, losses due to CSPWD was predicted to be about 
Table 5. Incidence of CSPWD in MYD × VTT "CSDP-replantings" (May 2007).

\begin{tabular}{|c|c|c|c|c|c|c|c|c|c|c|}
\hline \multicolumn{2}{|c|}{ Location } & \multicolumn{3}{|c|}{ Farms/Plots } & \multicolumn{3}{|l|}{ HA } & \multicolumn{3}{|l|}{ Palms } \\
\hline Reg & Distr & $\overline{\text { Pltd }}$ & Dis & $\%^{a}$ & $\overline{\text { PItd }}$ & Dis & $\%$ & $\overline{\text { Pltd }}$ & Dis & $\%$ \\
\hline \multirow[t]{5}{*}{ WR } & Ahanta West & 211 & 4 & 1.9 & 290 & 5 & 2.1 & 46,400 & 7 & 0.0002 \\
\hline & Nzema & 303 & 10 & 3.3 & 397 & 16 & 4.0 & 63,250 & 30 & 0.0005 \\
\hline & East & & & & & & & & & \\
\hline & SAEMA & 131 & 11 & 8.4 & 157 & 15 & 9.6 & 25,120 & 30 & 0.001 \\
\hline & Wassa West & 81 & 0 & 0 & 95 & 0 & 0 & 15,200 & 0 & 0.0 \\
\hline \multirow[t]{2}{*}{ CR } & AAK & 78 & 18 & 23.1 & 106 & 19 & 18.9 & 16,960 & 140 & 0.01 \\
\hline & KEEA & 221 & 7 & 3.2 & 255 & 7 & 2.8 & 40,800 & 145 & 0.004 \\
\hline Total & & 1,025 & 50 & 5.6 & 1,300 & 62 & 4.8 & 208,000 & 352 & 0.002 \\
\hline
\end{tabular}

Reg: region; Distr: district; Pltd: total planted; Dis: disease (CSPWD) level.

${ }^{a}$ : level of disease in percentage.

$64 \%$ in MYD $\times$ VTT plantings, but under the same conditions only $37 \%$ losses will be expected in the SGD $\times$ VTT [14]. The genetic modelling was found to show very good agreement between predicted and observed values and lends credence to the earlier assumption that the SGD $\times$ VTT should be a better alternative to MYD $\times$ VTT to replant devastated areas. The SGD $\times$ VTT hybrid is under screening at Agona Junction. From preliminary observations, the hybrid "promises" to show acceptable agronomic features [17], but its "field resistance" to CSPWD is yet to be tested, due to the absence of the disease in the plot since 2003. There are now two SGD seed gardens of 10 ha at Bonsaso and 5 ha at Kade, from which an SGD $\times$ VTT planting capacity of 200-300 ha per year is achievable [17].

The VTT parent occurs in subpopulations, as evidenced by distinct variation in fruit characteristics and colour. It is important to determine if all the "colour forms" are equally resistant to CSPWD. To resolve this, each of the different colour forms of the VTT has been crossed with SGD and the progenies planted in a "randomised complete block design" to test their performance. There are also experiments to separate the VTT into "pure lines" of its subpopulations, through "diallel-crosses", which could then be tested for their resistance. Dery et al. [14] suggested that the abnormal phenotypes of the SGD and VTT cultivars that succumbed to CSPWD at Axim and the single VTT that was killed by CSPWD after it was scorched by fire at Dixcove were due to some physiological malfunctioning or stress that could have compromised the inherent mechanism that conferred disease resistance to those ecotypes in the other trials. Figures 1 and 2 show some contrast between the morphological characteristics of the abnormal SCD and VTT palms at the Axim trials and the normal ones at the Agona Junction trials. Ashburner and Been [18] identified significant genotypic and environmental effects on the expression of resistance. Addison [7] and Harries [10] shared

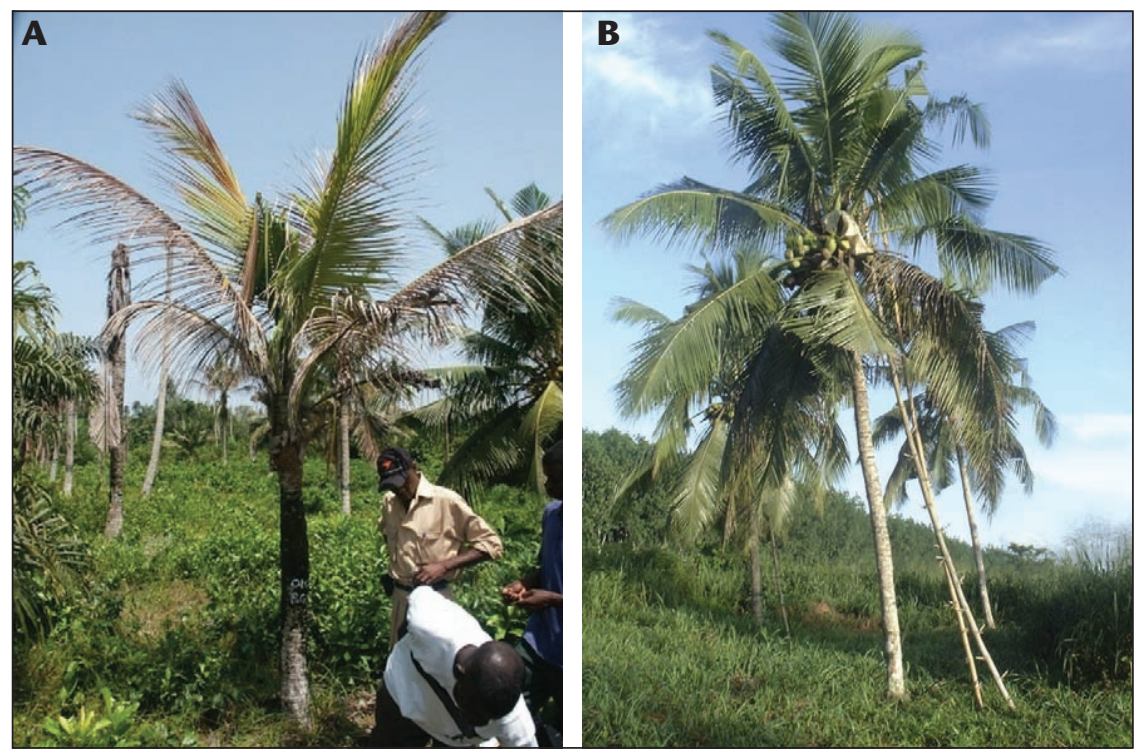

Figure 1. Growth habits of 25-year-old SCD palms at Axim and Agona Inc. Plots. A) Abnormal palm at Axim: stunted and vegetative only. B) Normal palm at Agona Inc: luxurious and good nut load.

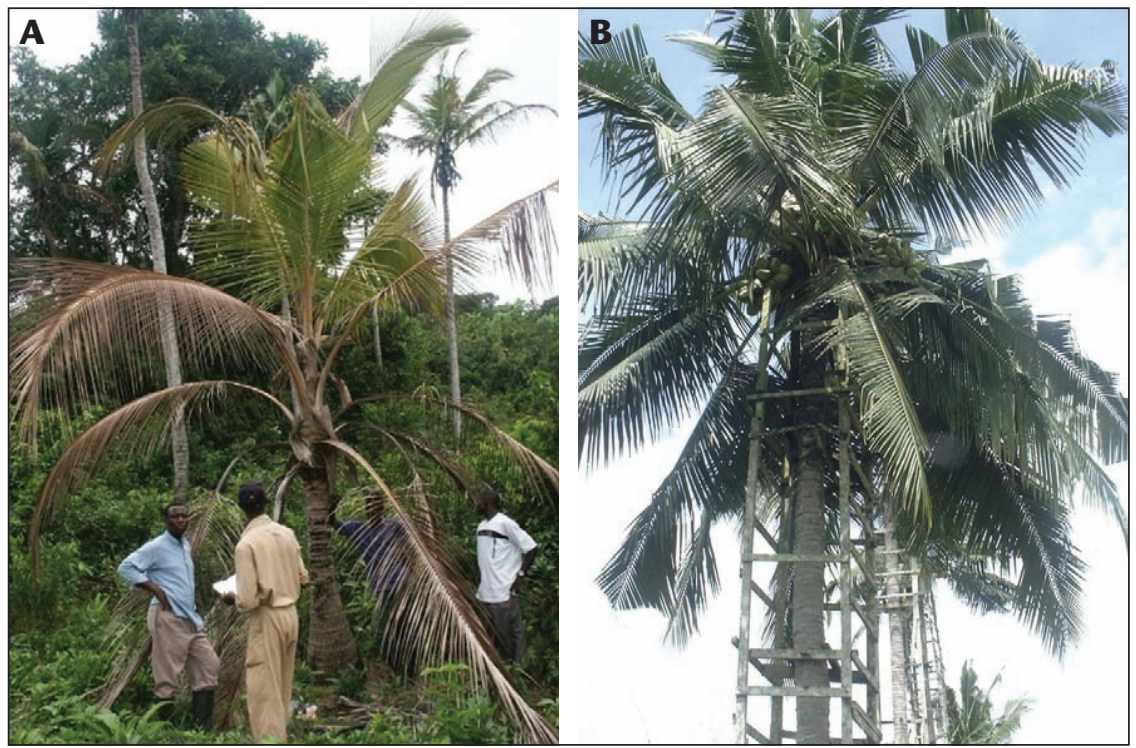

Figure 2. Growth habit of 25-year-old VTT palms at Axim and Agona Jnc. Plots. A) Abnormal palm at Axim: Stunted and vegetative only. B) Normal palm at Agona Jnc: luxurious and good nut load. 
the view that the environmental conditions at the Dzelukope area could have made the Malayan Dwarf tested there exceptionally susceptible to the disease. Harries [10] also lamented that soils with good drainage and fertility were reserved for high-value crops and coconuts get relegated to poor soils in drought-prone areas where they survive but do not thrive. Under such conditions it appears $\mathrm{LY}$ is able to overcome resistance. Harries suggested that 'if we could stop planting coconuts in suboptimal areas, we would perhaps make a positive step to controlling $L Y^{\prime}$ and believed that large-scale planting of resistant material should be undertaken only where growing conditions are good. The exceptionally high CSPWD incidence of $82 \%$ in a MYD $\times$ VTT replanting was attributed to unfavourable environmental conditions [14, 17]. To succeed in the fight against CSPWD, therefore, it seems logical that an integrated approach comprising resistant coconut varieties planted in suitable areas and with good cultural practices should be adopted.

\section{New replantings}

Dery et al. [14] recommended that due to the high performance of MYD $\times$ VTT exhibited in most places, it should not be abandoned, but be used to crop areas far removed from disease zones, where risk of CSPWD is minimal. In the endemic zones, it was recommended that only areas where the disease had "passed" and the disease pressure was very low could be cropped with SGD $\times$ VTT hybrid. Zones with active disease foci must not be planted with coconut. It must be ensured that good soil conditions and good agronomic practices prevail to ensure good growth of the palm. Effective phytosanitation should ensure prompt elimination of any infected palm, so as to check disease spread.

\section{Resistance Screening}

It is common knowledge that disease resistance is not a "once-forever" feature, it is therefore necessary that resistance screening in the country be continued. Dery, et al. [14] observed that cultivars from the Pacific group, especially the dwarfs, were less susceptible than the IndoAtlantic cultivars. Consequently, they recommended the introduction of more cultivars, especially Talls from the Pacific area (Southeast Asia) for testing. Additionally, due to the appreciable performance of SCD in Ghana (table 3), it should be worthwhile to test varieties that are genetically similar to the SGD. Dery, et al. [14] identified SGD and MRD as the most resistant varieties so far. It should be interesting to test the performance of the SGD $\times$ MRD hybrid against the CSPWD.

It will be important to use the microsatellite technique to confirm the identity of test palms, so as to determine "off-types" that could otherwise confuse and frustrate screening results, as could have happened in the Axim trial.

Acknowledgement. The resistance trials have been funded at different times by the Ghana Government, French Embassy (Accra), the EU (EC STD3 Project), the World Bank under the National Agricultural Research Project (NARP) and the Agricultural Services Sub-Sector Investment Project AgSSIP) and the Agence Francaise de Developpement (AFD). We acknowledge their support. We also wish to thank MrK. A. Yawson and the technical and field staff of the OPRI-Coconut Programme for their assistance with the data collection.

\section{REFERENCES}

1. Adam M, Arthur R, Duhamel G, Ghartey N, Overfield D, Willongby N. Analyses of Natural Resources utilization, livelihood systems, coping strategies and natural resource research needs in coconut growing areas of coastal zone ecosystems in Chana (phase I). NRI Document CO834 Vol. 1, May 1996.

2. Dery SK, Arthur R. Rehabilitation of Coconut Industry in Ghana: A Strategy. Coconut Project Document prepared for the Minister of Food and Agric, Western Region, September 1996.

3. Eden-Green. History, world distribution and represent status of lethal yellowing-like diseases of palms. In: Eden-Green S, Ofori F, eds. Proceedings of International Workshop on lethal yellowing-like diseases of Coconut. Elmina, Ghana, 5-10 November 1995. Chatham, UK: NRI, p. 9-25, 1997.

4. Howard FW, Norris RC, Thomas DL. Evidence of transmission of palm lethal yellowing agent by a planthopper, Myndus crudus (Homoptera: Cixiidae). Tropical Agric (Trinidad) 1983; 60: 168-71.

5. Hunt P, Dabek AJ, Schuiling M. Remission of symptoms following tetracylcline treatment of lethal yellowing infected coconut palms. Phytopath 1974; 64: 307-12.

6. Chona BL, Addoh PG. Cape St. Paul Wilt- The Present Position. In: Chona BL, Adansi MA, eds. Coconut In Chana. Bulletin No. 3, Crops Research Institute, CSIR, Ghana; pp 20.

7. Addison EA. Varietal resistance trials with some dwarf coconut palms against the Cape St Paul Wilt Disease in Ghana. Afr J PI Prot 1980; 1 : 129-41.
8. Ofori F, Nkansah-Poku J. Cape St Paul Wilt Disease of Coconut in Ghana. History of its occurrence and spread. In: Eden-Green S, Ofori F, eds. Proceedings of International Workshop on lethal yellowing-like diseases of Coconut, Elmina, Ghana, November 1995. Chatham, UK: NRI, p. 27-32, 1995.

9. Dery SK, Philippe R, Nkansah-Poku J, Arkhurst ED. Resistance screening and prospects for rehabilitating the coconut industry in Chana. In: S. Cape St Paul Wilt Disease. 1995.

10. Harries HC. Growing coconuts in Africa: resistance to lethal yellowing-like diseases. In: Eden-Grenn S, Ofori F, eds. Proceedings of International Workshop on lethal yellowing-like diseases of Coconut, Elmina, Ghana, 5-10 November. Chatham, UK: NRI, p. 139-146, 1995.

11. De Taffin G, Le Saint JP. Project on the Western Region Coconut Disease (Ghana). Report on the Mission undertaken on 25-31 January. Paris, France: IRHO, 1987.

12. Mariau D, Dery SK, Sangare A, N'Cho YP, Philippe R. Coconut lethal yellowing disease and planting material tolerance. Plantation Recherche Dev 1996; 3: 105-12.

13. Dery SK, N'Cho YP, Quaicoe RN, Arkhurst ED, Philippe R. Screening for resistance to lethal yellowing disease of coconuts in Ghana: an update of trial results. 1999. Plant Diseases: www.plantapalm.com/vpe/disease/vpe.coconutly1.htm

14. Dery SK, Philippe R, Baudouin L, et al. Genetic diversity among coconut varieties for susceptibility to Cape St Paul Wilt Disease. Euphytica 2008; 164: 1-11.

15. Been BO. Observations on field resistance to lethal yellowing in coconut varieties and hybrids in Jamaica. Oléagineux 1981; 36: 9-11.

16. Dery SK, Owusu Nipah J, Andoh-Mensah E, Nuertey BN, Nkansah-Poku J, Arthur R, Philippe R. On-farm evaluation of the coconut hybrid, Malayan Yellow Dwarf $x$ Vanuatu Tall, for tolerance to the lethal yellowing disease of coconut in Ghana. Cord 2005; 21: 50-6.

17. Dollet M, Bonneau X, Baudouin L. Which coconut palm for Lethal Yellowing in Ghana? Report on the mission from 11 to 18 June 2006. CIRAD-Cp; CP-1995, 2006.

18. Ashburner GR, Been BO. Characterization of resistance to lethal yellowing in Cocos nucifera and implications for genetic improvement of this species in the Caribbean Region. In: EdenGreen S, Ofori F, eds. Proceedings of International Workshop on lethal yellowing-like diseases of Coconut. Elmina, Ghana, November 1995. Chatham, UK : NRI, p. 173-183, 1997. 